\title{
A retrospective study on combination therapy with ifosfamide, adriamycin and cisplatin for progressive or recurrent uterine sarcoma
}

\author{
WATARU YAMAGAMI, NOBUYUKI SUSUMU, TOMOMI NINOMIYA, MICHIKO KUWAHATA, \\ AYA TAKIGAWA, HIROYUKI NOMURA, FUMIO KATAOKA, EIICHIRO TOMINAGA, \\ KOUJI BANNO, HIROSHI TSUDA and DAISUKE AOKI
}

\begin{abstract}
Department of Obstetrics and Gynecology, School of Medicine, Keio University, Shinjuku, Tokyo 160-8582, Japan
\end{abstract}
Received January 15, 2014; Accepted March 20, 2014

DOI: $10.3892 / \mathrm{mco} .2014 .272$

\begin{abstract}
There is currently insufficient evidence to recommend a specific chemotherapeutic regimen as standard treatment for uterine sarcomas. In this study, we investigated the toxicity and effectiveness of ifosfamide, adriamycin and cisplatin (IAP therapy) in patients with progressive and recurrent uterine sarcoma. A total of 11 patients with progressive or recurrent uterine sarcoma containing leiomyosarcoma (LMS), undifferentiated endometrial sarcoma (UES) or adenosarcoma, who were diagnosed at our institution, were retrospectively investigated. We recorded the adverse events, response rate and progression-free survival in these cases. The histological types included LMS (54.5\%), adenosarcoma (27.3\%) and UES (18.2\%). Grade $\geq 3$ leukopenia or neutropenia were observed in all the cases, febrile neutropenia developed in $45.5 \%$ of the patients and grade 4 thrombocytopenia developed in 3 cases (27.3\%). With IAP therapy, the response rate was $36.4 \%$ and the disease control rate was $90.9 \%$. Therefore, IAP therapy may be a viable option as chemotherapy for uterine sarcoma.
\end{abstract}

\section{Introduction}

Uterine sarcomas are extremely rare, non-epithelial malignant uterine tumors. Uterine sarcomas account for $8 \%$ of all malignant tumors of the corpus uteri and the most common histological types are carcinosarcoma (CS), leiomyosarcoma (LMS) and endometrial stromal sarcoma (ESS), in decreasing order of frequency (1). In Japan, it was reported that the most common histological types are CS (46\%), LMS (36\%) and ESS (13\%) (2). CS is a malignant tumor consisting of an epithelial and a nonepithelial component, which mainly affects postmenopausal

Correspondence to: Dr Wataru Yamagami, Department of Obstetrics and Gynecology, School of Medicine, Keio University, 35 Shinanomachi, Shinjuku, Tokyo 160-8582, Japan

E-mail: gami@z8.keio.jp

Key words: chemotherapy, adriamycin, ifosfamide, cisplatin, uterine sarcoma women. A combination tumor theory suggested that the majority of CSs originate from a single cell and differentiate into epithelioid-like and stromal-like components, whereas they are considered to exhibit cellular characteristics and progression similar to those of poorly differentiated endometrioid adenocarcinoma (3). Therefore, CSs tend to be treated in accordance with the treatment for epithelial endometrial cancer. However, LMS and ESS possess totally different properties compared to epithelial endometrial cancer.

LMS and ESS are malignant tumors that are mainly encountered during the perimenopausal period. Uterine leiomyomas may exhibit malignant transformation to LMS in $0.13-0.81 \%$ of the cases (4). These tumors are diagnosed based on the number of mitoses, degree of cellular atypia and presence of coagulation necrosis. ESS may be classified as low- or high-grade, based on the number of mitoses. However, these sarcomas are currently considered as different types of tumors. High-grade ESS, in particular, is referred to as undifferentiated endometrial sarcoma (UES). Total hysterectomy and bilateral salpingo-oophorectomy (BSO) are currently considered the first choice for the treatment of uterine sarcomas, although a consensus has not been reached regarding retroperitoneal lymphadenectomy $(5,6)$. However, these tumors cannot be sufficiently controlled by surgical treatment alone, since a number of patients develop progression and recurrence of uterine sarcoma. As LMS often develops distant hematogenous metastases to the lungs and the liver, chemotherapy is commonly required as a systemic treatment. However, there is insufficient evidence to recommend a specific chemotherapeutic regimen as standard treatment for uterine sarcomas, as these are rare tumors and the number of reported cases is limited.

We administered a combination of ifosfamide (IFM), adriamycin (ADM) and cisplatin (CDDP) (IAP therapy) to patients with progressive and recurrent uterine sarcomas and retrospectively investigated treatment effectiveness and toxicity.

\section{Patients and methods}

Patients. We investigated 11 patients who were diagnosed with uterine sarcoma and treated with IAP between 1990 and 2010 at the Keio University Hospital, Tokyo, Japan. 
Total hysterectomy and BSO or tumorectomy were performed in our hospital. The pathological diagnosis in all the cases was LMS, UES or adenosarcoma. The median follow-up period was 298 days (range, 36-2,757 days). Remission induction chemotherapy was performed in all the cases, as 8 of the patients had progressive disease (PD) and 3 patients had recurrent disease.

This study was approved by the Keio University School of Medicine Ethics Committee (approval no. 20120236) and all the patients provided informed consent.

Treatment plan. The treatment schedule was based on a case report of uterine sarcoma that was treated with $\operatorname{IAP}(7,8)$. The administration was every 3 weeks as follows: IFM $1.5 \mathrm{~g} /$ body on days $1-5$, mesna $900 \mathrm{mg} /$ body on days $1-5$, ADM $50 \mathrm{mg} / \mathrm{m}^{2}$ on day 1 and CDDP $50 \mathrm{mg} / \mathrm{m}^{2}$ on day 1 , intravenously. Granulocyte colony-stimulating factor (G-CSF) was used according to the criteria of the American Society of Clinical Oncology. This treatment schedule was repeated every 3 weeks until disease progression or until discontinuation due to adverse events.

Evaluation of response and toxicity. The adverse events were assessed according to the Common Terminology Criteria for Adverse Events, version 4.0, based on the interviews and blood tests conducted once a week or more frequently after each cycle. The subsequent cycle was initiated after the adverse events were resolved. As regards hematotoxicity, if patients presented with grade 4 leukopenia or neutropenia for $>7$ days, grade 3-4 thrombocytopenia, or febrile neutropenia, we considered reducing the dose or withdrawing drugs for the subsequent cycle.

We assessed the overall response rate of 11 cases who had received remission induction therapy and had evaluable lesions in accordance with the World Health Organization evaluation criteria and recorded the progression-free survival. The tumors were measured by computed tomography after every 2 cycles. After the product of the two longest perpendicular diameters was calculated, the response was assessed as follows: complete response (CR), complete disappearance of all known lesions for a minimum of 4 weeks; partial response (PR), $>50 \%$ reduction in the sum of the length $\mathrm{x}$ width of each measurable lesion for a minimum of 4 weeks; PD, $>25 \%$ increase in the sum of the products of all measurable lesions or appearance of any new lesions; no change (NC), any outcome that did not qualify as response or progression.

Statistical analysis. SPSS software, version 20 (IBM-SPSS Software, Chicago, IL, USA) was used for statistical analysis, using Fisher's exact test. $\mathrm{P}<0.05$ was considered to indicate a statistically significant difference. Kaplan-Meier curves were used for the estimation of progression-free survival and were compared with standard log-rank tests.

\section{Results}

Clinicopathological characteristics. The clinicopathological characteristics of the 11 cases who underwent IAP therapy are presented in Tables I and II. The median age at IAP therapy was 50 years (range, $34-72$ years). The primary tumor sites
Table I. Clinicopathological characteristics of the 11 cases.

\begin{tabular}{lr}
\hline Characteristics & No. \\
\hline Age (years) & 5 \\
$<50$ & 6 \\
$\geq 50$ & \\
Origin & 10 \\
Uterus & 1 \\
Retroperitoneum & \\
Histological type & 6 \\
Leiomyosarcoma & 3 \\
Adenosarcoma & 2 \\
Undifferentiated endometrial sarcoma & \\
Stage (FIGO 1988) & 4 \\
I & 0 \\
II & 1 \\
III & \\
IV & 5 \\
Other & 1 \\
Type of disease & \\
Progressive & \\
Recurrent & \\
Initial treatment & \\
Surgery & \\
Chemotherapy & 1 \\
Type of surgery & 1 \\
Hysterectomy + BSO (USO) & 5 \\
Other & \\
Chemotherapy prior to IAPa & \\
None & \\
CYVADIC & \\
DOC + GEM & \\
& \\
\hline
\end{tabular}

afosfamide, adriamycin and cisplatin. ${ }^{\mathrm{b}} \mathrm{Cyclophosphamide,} \mathrm{vincris-}$ tine, adriamycin and dacarbazine. FIGO, International Federation of Gynecology and Obstetrics; BSO, bilateral salpingo-oophorectomy; USO, unilateral salpingo-oophorectomy; DOC, docetaxel; GEM, gemcitabine.

were the uterus (10 cases, $90.9 \%)$ or the retroperitoneum (1 case, 9.1\%). The histological types were LMS (6 cases, 54.5\%), adenosarcoma (3 cases, 27.3\%) and UES (high-grade ESS; 2 cases, $18.2 \%)$.

Treatment. A total of 2 cases (18.2\%) had received pretreatment; 1 case had received cyclophosphamide, vincristine, ADM and dacarbazine (DTIC) (CYVADIC therapy) and 1 case had received docetaxel (DOC) + gemcitabine (GEM).

The median number of cycles of IAP therapy was 6 (range, 1-8 cycles). In $72.7 \%$ of the cases, a dose reduction was required. Among cases who received $>6$ cycles, in particular, $71.4 \%$ required a dose reduction. The chemotherapy was interrupted after 1 to 2 cycles for the patients who requested treatment discontinuation due to intolerable adverse events.

Adverse events. The adverse events of IAP therapy are summarized in Table III. Hematotoxicity, particularly grade $\geq 3$ 
Table II. Clinicopathological and treatment details of the 11 cases.

\begin{tabular}{|c|c|c|c|c|c|c|c|c|c|}
\hline $\begin{array}{l}\text { Age at } \\
\text { diagnosis } \\
\text { (years) }\end{array}$ & $\begin{array}{l}\text { Age } \\
\text { at IAPa } \\
\text { therapy } \\
\text { (years) }\end{array}$ & $\begin{array}{l}\text { Histological } \\
\text { type }\end{array}$ & $\begin{array}{l}\text { Disease } \\
\text { status }\end{array}$ & Initial treatment & $\begin{array}{c}\text { Prior } \\
\text { chemotherapy }\end{array}$ & $\begin{array}{l}\text { No. } \\
\text { of } \\
\text { cycles }\end{array}$ & Effectiveness & $\begin{array}{l}\text { Recurrence } \\
\text { after } \\
\text { IAP }^{\mathrm{a}} \text { therapy }\end{array}$ & $\begin{array}{l}\text { PFS } \\
\text { (days) }\end{array}$ \\
\hline 33 & 34 & Leiomyosarcoma & Recurrent & $\mathrm{ATH}+\mathrm{BSO}$ & CYVADIC $^{\mathrm{b}}$ & 8 & SD & Yes & 1,321 \\
\hline 67 & 72 & Adenosarcoma & Recurrent & $\mathrm{ATH}+\mathrm{BSO}$ & - & 2 & SD & No & - \\
\hline 51 & 51 & Leiomyosarcoma & Recurrent & Tumorectomy + BSO & - & 3 & $\mathrm{CR}$ & Yes & 213 \\
\hline 62 & 62 & Leiomyosarcoma & Progressive & Tumorectomy & - & 8 & SD & Yes & 125 \\
\hline 57 & 56 & ESS, high-grade & Progressive & Virchow LN biopsy & - & 1 & SD & Yes & 307 \\
\hline 43 & 43 & Adenosarcoma & Progressive & $\begin{array}{l}\mathrm{ATH}+\mathrm{BSO}+\mathrm{PLN}+ \\
\mathrm{OMT}+\text { tumorectomy }\end{array}$ & - & 6 & SD & Yes & 44 \\
\hline 50 & 50 & ESS, high-grade & Progressive & $\mathrm{ATH}+\mathrm{BSO}$ & - & 2 & SD & Unknown & - \\
\hline 40 & 40 & Leiomyosarcoma & Progressive & $\begin{array}{l}\mathrm{ATH}+\mathrm{BSO}+\mathrm{PLN} \\
+ \text { tumorectomy }\end{array}$ & - & 8 & PD & Yes & 25 \\
\hline 38 & 39 & Adenosarcoma & Progressive & $\mathrm{ATH}+$ tumorectomy & - & 6 & PR & Yes & 80 \\
\hline 35 & 35 & Leiomyosarcoma & Progressive & $\mathrm{ATH}+\mathrm{BSO}$ & $\mathrm{DOC}+\mathrm{GEM}$ & 6 & $\mathrm{CR}$ & No & - \\
\hline 56 & 57 & Leiomyosarcoma & Progressive & Tumorectomy & - & 6 & $\mathrm{CR}$ & Yes & 1,539 \\
\hline
\end{tabular}

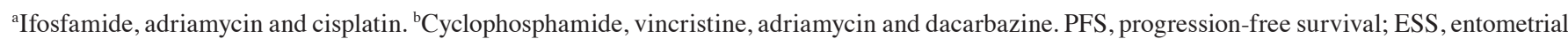
stromal sarcoma; ATH, abdominal total hysterectomy; BSO, bilateral salpingo-oophorectomy; LN, lymph node; PLN, pelvic lymphadenectomy; OMT, omentectomy; DOC, docetaxel; GEM, gemcitabine; SD, stable disease; CR, complete response; PD, progressive disease; PR, partial response.

leukopenia or neutropenia, developed in all the cases during the first cycle. Febrile neutropenia developed in $45.5 \%$ of the cases and resolved with administration of antibiotics and G-CSF. Grade 4 thrombopenia developed in 3 cases $(27.3 \%$ ), one of which required a platelet transfusion. Non-hematological adverse events other than anorexia, nausea and vomiting were not reported. Hemorrhagic cystitis or cardiotoxicity, which are adverse events characteristic of IFM and ADM, were also not reported.

Effectiveness. The therapeutic effects of remission induction chemotherapy are presented in Fig. 1 . The sum of CR + PR was $36.4 \%$ (95\% CI: 8.0-64.8\%) and that of CR + PR + NC was $90.9 \%$ (95\% CI: 73.9-100\%). The median progression-free survival was 307 days (95\% CI: 168-446 days).

\section{Discussion}

Although several chemotherapeutic options for uterine sarcoma were previously suggested, the number of large-scale studies on uterine sarcomas is limited, as this type of tumor is relatively rare. The overall rate of response to single-agent chemotherapy is presented in Table IV. The response rate for ADM, IFM and gemcitabine (GEM) was 25.0, 17.0 and $21.0 \%$, respectively (9-11); these are considered to be the key drugs in the treatment of uterine sarcoma. However, the response rate with paclitaxel and CDDP was 9.0 and $3.0 \%$, respectively $(12,13)$; thus, these drugs are considered to be less effective.

The efficiency of multi-agent chemotherapy for uterine sarcoma is summarized in Table V. Omura et al (9) investigated the efficiency of ADM + DTIC therapy and reported that, among 66 cases with measurable lesions of uterine sarcoma, $16(24.2 \%)$ achieved a remission (CR + PR). Specifically, the response rate was $30.0 \%(6 / 20)$ in cases with LMS.
Table III. Adverse events following IAP ${ }^{a}$ therapy.

\begin{tabular}{lccc}
\hline Adverse events & Grade & $\mathrm{N}$ & $\%$ \\
\hline Hematological & & & \\
Leukopenia & 3 & 2 & 18.2 \\
& 4 & 9 & 81.8 \\
Neutropenia & 3 & 2 & 18.2 \\
& 4 & 9 & 81.8 \\
Febrile neutropenia & 3 & 5 & 45.5 \\
Thrombocytopenia & 4 & 3 & 27.3 \\
Non-hematological & 3 & 0 & 0 \\
& 4 & 0 & 0 \\
\hline
\end{tabular}

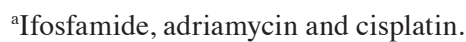

Sutton et al (14) investigated ADM + IFM therapy in 33 patients with LMS. As regards adverse events, grade $>3$ neutropenia developed in 17 cases $(48.6 \%)$, of which 2 developed febrile neutropenia. Grade $\geq 3$ thrombocytopenia was observed in 2 cases and nephrotoxicity in 1 case. There were 2 reported deaths due to the development of severe adverse events, specifically sepsis and cardiotoxicity. CR was achieved in 1 case and PR in 9 cases. The overall response rate was $30.3 \%$ and the disease control rate $(\mathrm{CR}+\mathrm{PR}+\mathrm{SD})$ was $82.0 \%$.

Piver et al (15) investigated CYVADIC therapy in 26 patients with intrapelvic sarcoma. As regards adverse events, neurotoxicity was observed in 8 cases $(30.7 \%)$, including 6 mild-to-moderate and 2 severe cases. No patient developed cardiotoxicity. However, sepsis developed in 4 cases $(15.3 \%)$ and 1 patient succumbed to the complications. The effectiveness was determined in 10 uterine sarcoma cases. The overall response rate and disease control rate were 20.0 and $60.0 \%$, respectively. 
Table IV. Overall rate of response to single-agent chemotherapy.

\begin{tabular}{|c|c|c|c|c|}
\hline Agents & Dose and regimen & Response rate $(\%)$ & First author & Refs. \\
\hline $\mathrm{ADM}$ & $60 \mathrm{mg} / \mathrm{m}^{2}$ day 1 & 25 & Omura & (9) \\
\hline Etoposide & $100 \mathrm{mg} / \mathrm{m}^{2}$ day $1-3$ & 11 & Slayton & (19) \\
\hline CDDP & $50 \mathrm{mg} / \mathrm{m}^{2}$ day 1 & 3 & Thigpen & (13) \\
\hline Ifosfamide & $1.5 \mathrm{~g} / \mathrm{m}^{2}$ day $1-5$ & 17 & Sutton & (10) \\
\hline Paclitaxel & $175 \mathrm{mg} / \mathrm{m}^{2}$ day 1 & 9 & Sutton & (12) \\
\hline Gemcitabine & $50 \mathrm{mg} / \mathrm{m}^{2}$ day 1,8 and 15 & 21 & Look & (11) \\
\hline Liposomal doxorubicin & $50 \mathrm{mg} / \mathrm{m}^{2}$ day 1 & 14 & Sutton & (20) \\
\hline Topotecan & $1.5 \mathrm{mg} / \mathrm{m}^{2}$ day $1-5$ & 11 & Miller & $(21)$ \\
\hline Trabectedin & $1.5 \mathrm{mg} / \mathrm{m}^{2}$ day 1 & 10 & Monk & (22) \\
\hline
\end{tabular}

ADM, adriamycin; CDDP, cisplatin.

Table V. Overall rate of response to multi-agent chemotherapy.

\begin{tabular}{|c|c|c|c|c|c|c|}
\hline Agents & Dose and regimen & Cases & Response rate $(\%)$ & Disease control rate $(\%)$ & First author & Refs. \\
\hline $\mathrm{ADM}+\mathrm{DTIC}$ & $\begin{array}{l}\text { ADM } 60 \mathrm{mg} / \mathrm{m}^{2} \text { day } 1 \\
\text { DTIC } 250 \mathrm{mg} / \mathrm{m}^{2} \text { days } 1-5\end{array}$ & 20 & 30.0 & & Omura & (9) \\
\hline $\mathrm{IFM}+\mathrm{ADM}$ & $\begin{array}{l}\text { IFM } 5 \mathrm{~g} / \mathrm{m}^{2} \text { day } 1 \\
\text { ADM } 50 \mathrm{mg} / \mathrm{m}^{2} \text { day } 3\end{array}$ & 33 & 30.3 & 81.8 & Sutton & (14) \\
\hline CYVADIC & $\begin{array}{l}\text { CPA } 400 \mathrm{mg} / \mathrm{m}^{2} \text { day } 2 \\
\text { Vicristine } 1 \mathrm{mg} / \mathrm{m}^{2} \text { days } 1-5 \\
\text { ADM } 40 \mathrm{mg} / \mathrm{m}^{2} \text { day } 2 \\
\text { DTIC } 200 \mathrm{mg} / \mathrm{m}^{2} \text { days } 1-5\end{array}$ & 10 & 20.0 & 60.0 & Piver & (15) \\
\hline GEM + DOC & $\begin{array}{l}\text { GEM } 900 \mathrm{mg} / \mathrm{m}^{2} \text { day } 1 \\
\text { DOC } 100 \mathrm{mg} / \mathrm{m}^{2} \text { days } 1 \text { and } 8\end{array}$ & 42 & 35.8 & 62.0 & Hensley & $(16,17)$ \\
\hline MAID & $\begin{array}{l}\text { Mesna } 1.5 \mathrm{~g} / \mathrm{m}^{2} \text { days } 1-4 \\
\text { IFM } 1.5 \mathrm{~g} / \mathrm{m}^{2} \text { days } 1-3 \\
\text { ADM } 15 \mathrm{mg} / \mathrm{m}^{2} \text { days } 1-3 \\
\text { DTIC } 250 \mathrm{mg} / \mathrm{m}^{2} \text { days } 1-5\end{array}$ & 6 & 33.3 & 50.0 & Pearl & (18) \\
\hline IAP & $\begin{array}{l}\text { IFM } 1.5 \mathrm{~g} / \text { body days } 1-5 \\
\text { ADM } 50 \mathrm{mg} / \mathrm{m}^{2} \text { day } 1 \\
\text { CDDP } 50 \mathrm{mg} / \mathrm{m}^{2} \text { day } 1\end{array}$ & 11 & 36.4 & 90.9 & Present study & \\
\hline
\end{tabular}

ADM, adriamycin; CPA, cyclophosphamide; GEM, gemcitabine; DTIC, dacarbazine; DOC, docetaxel; IFM, ifosfamide; CDDP, cisplatin.

$\mathbf{A}$

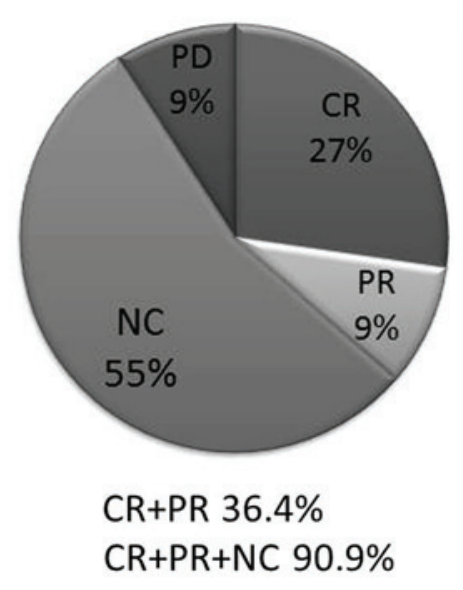

B

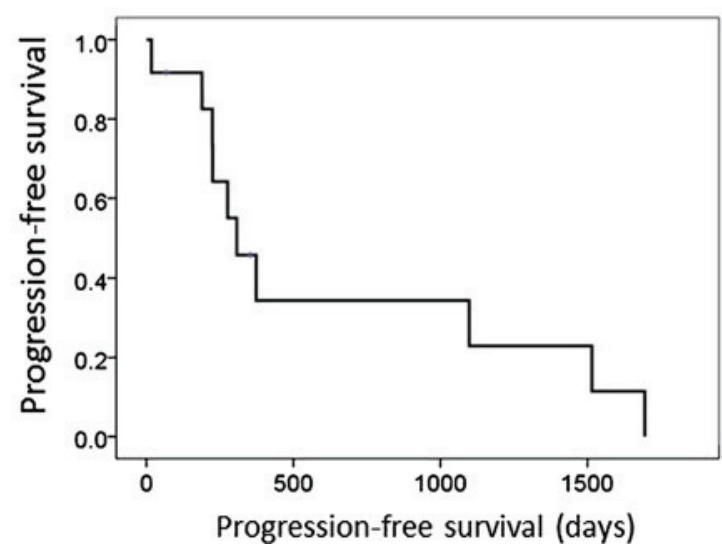

Figure 1. Therapeutic effects of remission induction chemotherapy. (A) The overall response rate was $36.4 \%$ and the disease control rate, including NC, was 90.9\%. (B) The median progression-free survival was 307 days (95\% CI: 168-446 days). NC, no change; CR, complete response; PR, partial response; PD, progressive disease. 
Hensley et al $(16,17)$ investigated docetaxel (DOC) + GEM therapy in 42 patients with uterine LMS. The adverse events were grade $\geq 3$ neutropenia in $17.0 \%$, grade $\geq 3$ anemia in $24.0 \%$ and grade $\geq$ thrombocytopenia in $14.5 \%$ of the cases. Grade 3 allergic reactions and grade 4 pulmonary toxicity developed in all the patients. As regards effectiveness, the overall response rate was $35.8 \%$ and the disease control rate was $62.0 \%$.

Pearl et al (18) investigated MAID therapy in 23 patients with gynecological sarcoma, including uterine LMS and adenosarcoma. The overall response rate was $33.3 \%$ and the disease control rate was $50.0 \%$.

The number of studies on IAP therapy for uterine sarcoma is currently limited. Yamawaki et al (6) reported that IAP was effective in a case with progressive UES. Yamaguchi et al (23) also reported that the rate of PR with IAP therapy for uterine sarcomas was $40.0 \%$ in the first-line and $9.1 \%$ in the second-line chemotherapy setting.

In this study, IAP therapy achieved an overall response rate of $36.4 \%$ and a disease control rate, including NC, of $90.9 \%$. Our results were comparable to those of IFM + ADM or DOC + GEM therapy. The adverse events recorded in the present study were mainly hematological, with grade $\geq 3$ leukopenia and neutropenia in all the cases. However, these adverse events were manageable with dose reduction and G-CSF administration for severe hematotoxicity. Only one patient experienced severe thrombocytopenia requiring platelet transfusion. The median number of administered cycles was 6 . There were no severe non-hematological complications or treatment-related deaths in the present study.

In conclusion, taking into consideration the abovementioned findings, IAP therapy may be a feasible chemotherapeutic option for progressive or recurrent uterine sarcoma.

\section{Acknowledgements}

The authors would like to thank Ms. Keiko Abe and Ms. Tomomi Noda for their secretarial assistance.

\section{References}

1. Brooks SE, Zhan M, Cote T and Baquet CR: Surveillance, epidemiology, and end results analysis of 2,677 cases of uterine sarcoma 1989-1999. Gynecol Oncol 93: 204-208, 2004.

2. Fujita H, Adachi S, Kigawa J, et al. Clinicopathological analysis for uterine sarcoma. Sampu no shimpo 56: 463-465, 2004 (In Japanese).

3. Wada H, Enomoto T, Fujita M, et al: Molecular evidence that most but not all carcinosarcomas of the uterus are combination tumors. Cancer Res 57: 5379-5385, 1997.

4. Lurain JR: Uterine cancer. In: Berek \& Novak's Gynecology. Berek JS (ed). 14th edition, Lippincott Williams \& Wilkins, Philadelphia, pp1343-1402, 2006.

5. Goff BA, Rice LW, Fleischhacker D, et al: Uterine leiomyosarcoma and endometrial stromal sarcoma: lymph node metastases and sites of recurrence. Gynecol Oncol 50: 105-109, 1993.

6. Sagae S, Yamashita K, Ishioka S, et al: Preoperative diagnosis and treatment results in 106 patients with uterine sarcoma in Hokkaido, Japan. Oncology 67: 33-39, 2004.
7. Ushijima M, Yamakawa Y, Sakabe E, et al: A case of recurrent high-grade endometrial stromal sarcoma controlled by a combination of ifosfamide, adriamycin, and cisplatin. Jpn J Canc Chemother 37: 2003-2005, 2010 (In Japanese).

8. Yamawaki T, Shimizu Y and Hasumi K: Treatment of stage IV 'high-grade' endometrial stromal sarcoma with ifosfamide, adriamycin, and cisplatin. Gynecol Oncol 64: 265-269, 1997.

9. Omura GA, Major FJ, Blessing JA, et al: A randomized study of adriamycin with and without dimethyl triazenoimidazole carboxamide in advanced uterine sarcomas. Cancer 52: 626-632, 1983.

10. Sutton GP, Blessing JA, Manetta A, et al: Gynecologic Oncology Group studies with ifosfamide. Semin Oncol 19: 31-34, 1992.

11. Look KY, Sandler A, Blessing JA, Lucci JA III and Rose PG; Gynecologic Oncology Group (GOG): Phase II trial of gemcitabine as second-line chemotherapy of uterine leiomyosarcoma: a Gynecologic Oncology Group (GOG) study. Gynecol Oncol 92: 644-647, 2004.

12. Sutton G, Blessing JA and Ball H: Phase II trial of paclitaxel in leiomyosarcoma of the uterus: a Gynecologic Oncology Group study. Gynecol Oncol 74: 346-349, 1999.

13. Thigpen JT, Blessing JA, Beecham J, Homesley $H$ and Yordan E: Phase II trial of cisplatin as first-line chemotherapy in patients with advanced or recurrent uterine sarcomas: a Gynecologic Oncology Group study. J Clin Oncol 9: 19621966, 1991.

14. Sutton G, Blessing JA and Malfetano JH: Ifosfamide and doxorubicin in the treatment of advanced leiomyosarcomas of the uterus: a Gynecologic Oncology Group study. Gynecol Oncol 62: 226-229, 1996.

15. Piver MS, DeEulis TG, Lele SB and Barlow JJ: Cyclophosphamide, vincristine, adriamycin, and dimethyl-triazeno imidazole carboxamide (CYVADIC) for sarcomas of the female genital tract. Gynecol Oncol 14: 319-323, 1982.

16. Hensley ML, Blessing JA, Degeest K, et al: Fixed-dose rate gemcitabine plus docetaxel as second-line therapy for metastatic uterine leiomyosarcoma: a Gynecologic Oncology Group phase II study. Gynecol Oncol 109: 323-328, 2008.

17. Hensley ML, Blessing JA, Mannel R and Rose PG: Fixed-dose rate gemcitabine plus docetaxel as first-line therapy for metastatic uterine leiomyosarcoma: a Gynecologic Oncology Group phase II trial. Gynecol Oncol 109: 329-334, 2008.

18. Pearl ML, Inagami M, McCauley DL, et al: Mesna, doxorubicin, ifosfamide, and dacarbazine (MAID) chemotherapy for gynecological sarcomas. Int J Gynecol Cancer 12: 745-748, 2002.

19. Slayton RE, Blessing JA, Angel C and Berman M: Phase II trial of etoposide in the management of advanced and recurrent leiomyosarcoma of the uterus: a Gynecologic Oncology Group Study. Cancer Treat Rep 71: 1303-1304, 1987.

20. Sutton G, Blessing J, Hanjani P and Kramer P; Gynecologic Oncology Group: Phase II evaluation of liposomal doxorubicin (Doxil) in recurrent or advanced leiomyosarcoma of the uterus: a Gynecologic Oncology Group study. Gynecol Oncol 96: 749-752, 2005.

21. Miller DS, Blessing JA, Kilgore LC, Mannel R and Van Le L: Phase II trial of topotecan in patients with advanced, persistent, or recurrent uterine leiomyosarcomas: a Gynecologic Oncology Group study. Am J Clin Oncol 23: 355-357, 2000.

22. Monk BJ, Blessing JA, Street DG, et al: A phase II evaluation of trabectedin in the treatment of advanced, persistent, or recurrent uterine leiomyosarcoma: a Gynecologic Oncology Group study. Gynecol Oncol 124: 48-52, 2012.

23. Yamaguchi M, Yanase T, Yokoo T, et al: Clinical study and treatment of uterine sarcoma at Niigata City General Hospital. Jpn J Canc Chemother 31: 209-213, 2004 (In Japanese). 